\title{
TRAIL inhibits angiogenesis stimulated by VEGF expression in human glioblastoma cells
}

\author{
G Cantarella', N Risuglia', R Dell'Eva ${ }^{2}$, L Lempereur', A Albini $^{2}$, G Pennisi $^{3}$, GM Scoto $^{4}$, DN Noonan $^{2}$ and $^{\prime}$ \\ R Bernardini*,I
}

'Department of Experimental and Clinical Pharmacology, University of Catania, Viale Andrea Doria, 6, Catania 95 I 25, Italy; ${ }^{2}$ Laboratory of Experimental Oncology, National Cancer Research Institute, Genova 16100, Italy; ${ }^{3}$ Department of Chemical Sciences, University of Catania, Catania 95 I 25, Italy;

${ }^{4}$ Department of Pharmaceutical Sciences, University of Catania, Catania 95/25, Italy

\begin{abstract}
Tumour growth is tightly related to new blood vessel formation, tissue remodelling and invasiveness capacity. A number of tissular factors fuel the growth of glioblastoma multiforme, the most aggressive brain neoplasm. In fact, gene array analyses demonstrated that the proapoptotic cytokine tumour necrosis factor-related apoptosis-inducing ligand (TRAIL) inhibited mRNA expression of VEGF, along with those of matrix metalloproteinase-2 (MMP-2), its inhibitor tissue inhibitor of matrix metalloproteinases-2 (TIMP-2), as well as the tumour invasiveness-related gene secreted protein acid rich in cysteine (SPARC) in different human glioblastoma cell lines. Particularly, VEGF mRNA and protein expression and release from glioblastoma cells were also inhibited by TRAIL. The latter also exerted antimitogenic effects on human umbilical vein endothelial cells (HUVECs). With the same cells, TRAIL inhibited new vessel formation in the in vitro matrigel model, as well as it exerted powerful inhibition of blood vessel formation induced by an angiogenic cocktail administered in subcutaneous pellets in vivo in the C57 mouse. Moreover, the expression of MMP-2, its inhibitor TIMP-2 and the tumour invasiveness-related protein SPARC were effectively inhibited by TRAIL in glioblastoma cell lines. In conclusion, our data indicate that TRAIL inhibits the orchestra of factors contributing to glioblastoma biological aggressiveness. Thus, the TRAIL system could be regarded as a molecular target to exploit for innovative therapy of this type of tumour.
\end{abstract}

British Journal of Cancer (2006) 94, I428-|435. doi:I0.1038/sj.bjc.6603092 www.bjcancer.com

Published online II April 2006

(c) 2006 Cancer Research UK

Keywords: brain tumour; endothelial cell; tissue remodelling; invasiveness

Formation of new blood vessels starting from pre-existing vascular structures is referred to as angiogenesis (Bussolino et al, 1998). Angiogenesis is dependent on an array of intrinsic stimulatory and inhibitory factors, interplaying among them with the aim to modulate both tissue matrix and cells participating in the process (Risau, 1997).

Vascular endothelial growth factor (VEGF) is the most specific among proangiogenic factors (Ferrara, 1993), whose expression is typically increased in normal and tumour cells at conditions of hypoxia (Ferrara and Davis Smyth, 1997). A quite large number of tumours are able to synthesise and actively release VEGF (Ferrara, 2005). Although of relevance, VEGF is not the sole factor concurring to angiogenesis. In fact, an array of regulatory molecules contributes substantially to the formation of new vessels (Folkman, 1995). For example, the proinflammatory macrophagic cytokine tumour necrosis factor- $\alpha$ (TNF- $\alpha)$ possesses direct proangiogenic properties (Vanderslice et al, 1998), and the TNFrelated apoptosis-inducing ligand (TRAIL) has been shown to affect the function of endothelial cells (Li et al, 2003).

TRAIL binds the two transmembrane, homotrimeric DR4 and DR5 death receptors, as well as two decoy receptors and

\footnotetext{
*Correspondence: Dr R Bernardini;

E-mail: bernardi@unict.it

Received 3 January 2006; revised 14 March 2006; accepted 14 March 2006; published online II April 2006
}

osteoprotegerin, involved in bone tissue remodelling (Almasan and Ashkenazi, 2003). Although biological effects of TRAIL were initially thought to be restricted to its typical tumour cell toxicity (Sheridan et al, 1997), numerous data report its proapoptotic effects on normal human cells, including brain cells (Nitsch et al, 2000). Interestingly, human glioblastoma cells, such as A172, U87MG and U373MG, display differential responsiveness to TRAIL-related cytotoxicity in vitro and in vivo (Pollack et al, 2001; Nabors et al, 2003; Kasuga et al, 2004), and also release substantial amounts of VEGF in response to hypoxia (Acker and Plate, 2004). Moreover, such a high angiogenic potential of glioblastoma appears associated with high expression of tissue remodelling-related molecules, such as the matrix metalloproteinase-2 (MMP-2) and its inhibitor, named tissue inhibitor of metalloproteinases-2 (TIMP-2), both concurring, along with angiogenesis, to tumour growth (Fillmore et al, 2001; VanMeter et al, 2001). Furthermore, glioblastoma growth is marked by severe dysfunction of molecules such as the secreted protein acid rich in cysteine (SPARC), which, in normal cells, restraints invasiveness and is actually being regarded as a candidate main enhancer of high tissue invasiveness (Golembieski and Rempel, 2002; Schultz et al, 2002).

Thus, in light of the reported effects of TRAIL on both tumour and endothelial cells, considering the high vascularisation index of glioblastomas (De Ridder et al, 1987), we first investigated the possible involvement of TRAIL in glioblastoma-related angiogenesis. 
To do so, we verified the hypothesis whether TRAIL could influence angiogenesis-related genes in both the three human glioblastoma cell lines A172, U87MG and U373MG, as well as in human umbilical vein endothelial cells (HUVECs), by means of a specific microarray (Zheng et al, 2000). In parallel, we also evaluated direct effects of TRAIL on endothelial cell function.

To verify the hypothesis that factors modulating angiogenesis might, in addition, influence tissue factors related to tumour progression, we studied TRAIL effects upon tissue remodelling and invasiveness gene expression in different glioblastoma cell lines.

\section{MATERIALS AND METHODS}

\section{Cell cultures and reagents}

All materials and media were from Invitrogen Srl (San Giuliano Milanese, Italy), unless otherwise specified.

The human glioblastoma cell lines A172, U87MG and U373MG, as well as both the HeLa and the MCF-7 cell lines, were routinely cultured in Dulbecco's modified Eagle's medium (DMEM) supplemented with $10 \%\left(\mathrm{vv}^{-1}\right)$ fetal bovine serum (FBS), $50 \mu \mathrm{g} \mathrm{ml}^{-1}$ penicillin and $100 \mu \mathrm{g} \mathrm{ml}^{-1}$ streptomycin, and kept at $37^{\circ} \mathrm{C}$ in humidified $5 \% \mathrm{CO}_{2} / 95 \%$ atmosphere.

HUVECs were obtained from human umbilical cords of healthy women undergone uncomplicated term pregnancies, as described elsewhere (Jaffe et al, 1973). HUVECs were grown in gelatin-coated plastic in medium M199 supplemented with endothelial cell growth supplement (ECGS; $20 \mu \mathrm{g} \mathrm{ml}^{-1}$ ), heparin $\left(1625 \mathrm{UI} \mathrm{ml}^{-1}\right.$ ) (Sigma-Aldrich, Milano, Italy) and 20\% FBS.

\section{Gene array}

Human Angiogenesis GEArray kit (SuperArray Inc., Bethesda, MD, USA), composed of 96 angiogenesis-related genes as well as two housekeeping genes, actin and glyceraldehyde-3-phosphate dehydrogenase (GADPH), was used to characterise gene expression profile of A172 cells after treatment with TRAIL $25 \mathrm{ng} \mathrm{ml}^{-1}$ (Alexis Biochemicals, San Diego, CA, USA) for 0, 6, 12 and $24 \mathrm{~h}$. Total RNA was isolated from cells after solubilisation in guanidinium thiocyanate by phenol-chloroform extraction and precipitation. cDNA probes for array analysis were synthesised following the manufacturer's directions. Differential gene expression patterns were detected by autoradiography. The experiments were repeated three times.

\section{Probe synthesis and Northern blot analysis}

The cDNA probes of the VEGF gene and the GADPH were synthesised by RT-PCR. For the human VEGF, we used a primer pair composed of the sense primer $5^{\prime}$-TTGCTGCTCTACCTCCAC $-3^{\prime}$ and the antisense primer $5^{\prime}$-AATGCTTTCTCCGCTCTG- $3^{\prime}$; for the human GADPH, the primer set was composed of the sense $5^{\prime}$-CCACCCATGGCAAATTCCATG-3' and antisense 5'-TCTAGA CGGCAGGTCAGGTCCACC-3'. The resulting cDNAs were purified by High Pure PCR pruduct (Boehringer, Mannheim, Germany) according to the manufacturer's protocol. Then, probes were labelled with $\left[{ }^{32} \mathrm{P}\right] \mathrm{dCTP}$ by random primer labelling. Northern hybridisation was performed according to standard protocols. The hybridised RNA was detected by autoradiography.

\section{Data analysis}

Scanlyser software developed by Micheal Eisen at Lawrence Berkeley National Laboratory and GEArray analyser software (by SuperArray Inc.) were used to analyse the gene spots and process data. First X-ray film-recorded array images were converted into raw data files by using scanlyser software. The data files were then processed with GEArray analyser software. Background subtraction was performed normalising the data to the negative control (bacterial plasmid pUC18). The gene expression levels in the different samples were then normalised to the housekeeping gene expression level of each array. The results were expressed as relative amounts in arbitrary units. The data were presented as the mean \pm s.e.m. of two different experiments in duplicate.

\section{Western blot analysis}

In a set of experiments, subconfluent glioblastoma cell lines grown in $60 \mathrm{~mm}$ plastic Petri dishes were starved for $24 \mathrm{~h}$ and then incubated in the presence of TRAIL $\left(25 \mathrm{ng} \mathrm{ml}^{-1}\right)$ for 12 and $24 \mathrm{~h}$. In other experiments, cells grown in $60 \mathrm{~mm}$ plastic Petri dishes, starved for $24 \mathrm{~h}$, were incubated in the presence of TRAIL $\left(25 \mathrm{ng} \mathrm{ml}^{-1}\right)$ or TNF $\alpha\left(25 \mathrm{ng} \mathrm{ml}^{-1}\right)$ for $24 \mathrm{~h}$, either alone or in combination. Cells were then lysed in NP-40 lysis buffer $(50 \mathrm{mM}$ HEPES, pH 7.6, $150 \mathrm{~mm} \mathrm{NaCl}, 50 \mu \mathrm{M} \mathrm{NaF}, 2 \mathrm{~mm}$ EDTA, $1 \mathrm{~mm}$ $\mathrm{Na}_{3} \mathrm{VO}_{4}, 1 \% \mathrm{NP}-40,2 \mathrm{~mm}$ PMSF) and cellular extracts (30 $\left.\mu \mathrm{g}\right)$ were processed for SDS-PAGE electrophoresis and nitrocellulose membrane transfer. Membranes were incubated with a rabbit polyclonal anti-hVEGF (Santa Cruz Biotechnology, Santa Cruz, CA, USA), mouse monoclonal anti-hMMP-2 (Chemicon International Inc., Temecula, CA, USA), mouse monoclonal anti-hTIMP-2 (Santa Cruz Biotechnology) or goat polyclonal anti-hSPARC antibody (Santa Cruz Biotechnology). Secondary antibodies (Amersham Life Science, Buckinghamshire, UK) and a chemiluminescence kit (Amersham) were used for immunodetection. For validation of blot data, densitometric analysis was performed on immunoblots by using a KLB 2222-020 Ultra Scan XL laser densitometer at a wavelength of $633 \mathrm{~nm}$. Western blot analysis was performed on samples from three separated experiments.

\section{ELISA test}

A specific double-antibody ELISA (Oncogene Research Product, San Diego CA, USA) was used to determine the concentration of VEGF in the media of different glioblastoma cells treated with TRAIL $\left(25 \mathrm{ng} \mathrm{ml}^{-1}\right)$ for $24 \mathrm{~h}$. The standard curve was generated using human recombinant $\mathrm{VEGF}_{165}$. The values of intra- and interassay variation were essentially within the range given by the manufacturer, that is, $3.5-6.5$ and $5.0-8.5 \%$, respectively. All values were assessed at least in quadruplicate.

\section{Viability assays}

A172, U87MG and U373MG human glioblastoma cells were seeded at $1 \times 10^{3}$ cells well $^{-1}$ in 96-multiwell plates containing DMEM, with $10 \%$ FCS, penicillin and streptomycin. After $24 \mathrm{~h}$, TRAIL was added at graded concentrations (range 12-200 $\mathrm{ng} \mathrm{ml}^{-1}$ ) for 24 additional hours.

HUVECs were seeded at $1 \times 10^{3}$ cells well $^{-1}$ into 96-multiwell plates in M199 with ECGS, 20\% FBS and heparin. After $24 \mathrm{~h}$, medium was replaced with fresh complete medium containing graded concentrations of TRAIL $\left(100,200\right.$ and $\left.400 \mathrm{ng} \mathrm{ml}^{-1}\right)$, and incubated for $24 \mathrm{~h}$.

At the end of all experiments, cells were stained with $0.5 \%$ crystal violet solution for $30 \mathrm{~min}$, washed with bidistilled water and lysed in $10 \%$ acetic acid for 15 min. Optical density was read at $570 \mathrm{~nm}$.

\section{In vivo experiments on angiogenesis}

Male C57BL/6 mice, 6-8 weeks old, were purchased from Charles River (Calco, Italy). In National Cancer Research Institute's Animal Facility, investigators can work with laboratory animals with respect to the national current regulations regarding the protection of animals used for scientific purpose (D.L.vo 27/01/ 
1992, no. 116) and research protocols were reviewed and approved by the Ethical Committee. All in vivo procedures met the standards required by the United Kingdom co-ordinating committee on cancer research (UKCCCR) guidelines. In addition, the animal study procedures were consistent and in accordance with the UKCCCR guidelines for the welfare of animals in experimental neoplasia (Workman et al, 1998).

The Matrigel sponge model of angiogenesis in vivo introduced by Passaniti et al (1992) and modified by Albini et al (1994, 1995) was used. VTH (50 $\mathrm{ng} \mathrm{ml}^{-1}$ VEGF, $2 \mathrm{ng} \mathrm{ml}^{-1}$ TNF- $\alpha$ and heparin) alone or in combination with TRAIL was added to unpolymerised liquid Matrigel at $4{ }^{\circ} \mathrm{C}$, and the mixture brought to a final volume of $600 \mu \mathrm{l}$. The Matrigel suspension was then injected slowly subcutaneously into the flanks of C57/bl6 male mice (six animals per group; housed in tight accordance to current GLP regulations and humane care; these procedures meet the standards required by the UKCCCR guidelines). In addition, the animal study procedures were consistent and in accordance with the UKCCCR guidelines for the welfare of animals in experimental neoplasia (Workman et al, 1998) with a cold syringe. At body temperature in vivo, the Matrigel quickly polymerises to form a solid gel. Different groups of animals were used for the different treatments. The control group was treated with vehicle alone; one group received TRAIL high dose (200 $\mathrm{n} \mathrm{ml}^{-1}$ ) with VTH in the Matrigel sponge, whereas another group received TRAIL low dose $\left(100 \mathrm{ng} \mathrm{ml}^{-1}\right)$ with VTH in the Matrigel sponge.

After 4 days, gels from all groups were collected and weighted. Samples were either minced and diluted in water to measure the haemoglobin content with a Drabkin reagent kit (Sigma) or processed for histology.

\section{Matrigel morphogenesis assay}

Matrigel was thawed at $4{ }^{\circ} \mathrm{C}$ in an ice/water bath, and $300 \mu \mathrm{lwell}^{-1}$ were carefully added to a 24 -microwell plate prechilled at $-20^{\circ} \mathrm{C}$ using a cold pipette. Matrigel was allowed to polymerise for $30 \mathrm{~min}$ at $37^{\circ} \mathrm{C}$. Once polymerisation had occurred, 70000 HUVEC cells well ${ }^{-1}$ in $1 \mathrm{ml}$ of complete medium were layered on the top of polymerised gel in the presence or absence of TRAIL at the concentrations indicated. The plates were then incubated at $37^{\circ} \mathrm{C}$ in a $5 \% \mathrm{CO}_{2}$, humidified atmosphere. After 6 and $24 \mathrm{~h}$, the wells were photographed with CCD optics and a digital analysis system (Image Pro Plus), respectively.

\section{Statistical analysis of results}

Results were analysed by either one- or two-way analysis of variance (ANOVA), followed by Duncan's least significant difference test. Where appropriate, the Student's ' $t$ '-test was applied. Significance was admitted for a $P$-value $<0.05$.

\section{RESULTS}

\section{Effects of TRAIL on human glioblastoma cell viability}

We first assessed TRAIL cytotoxicity on the glioblastoma cell lines A172, U87MG and U373MG. All glioblastoma cells treated with graded concentrations of TRAIL showed significant decrease of viability, reaching a peak at a concentration of $100 \mathrm{ng} \mathrm{ml}^{-1}$. All cells underwent death after $24 \mathrm{~h}$ treatment. On the other hand, only about $25 \%$ of cells were killed after $24 \mathrm{~h}$ of treatment with TRAIL $\left(25 \mathrm{ng} \mathrm{ml}^{-1}\right)$ (Figure 1A, graphs 1, 2 and 3).

Effects of TRAIL on human glioblastoma cell expression of genes related to angiogenesis, tissue remodelling and cell invasiveness

To study the effects of TRAIL on angiogenesis, we first investigated whether it could affect the expression of angiogenesis-related genes in glioblastoma cells. To do so, we performed multiple mRNA screening analysis in A172 cells treated with TRAIL.

The corresponding gene array analysis of A172 human glioblastoma cells treated with TRAIL showed that the response to TRAIL encompasses several angiogenesis-related genes.

Particularly, the expression of the following genes was affected in A172 cells after $24 \mathrm{~h}$ of treatment with TRAIL: VEGF, the MMP2 , the gene encoding TIMP-2, a protein regulating the activity of MMP-2 and SPARC, a protein involved in glioblastoma invasiveness processes (Figure 2A).

Effects of TRAIL upon the angiogenic potential of human glioblastoma cells: inhibitory effects of TRAIL on VEGF mRNA and protein

As VEGF expression was affected in A172 cells treated with TRAIL, we first attempted to measure changes in VEGF mRNA amounts by Northern blot analysis in cultures treated with TRAIL. The data
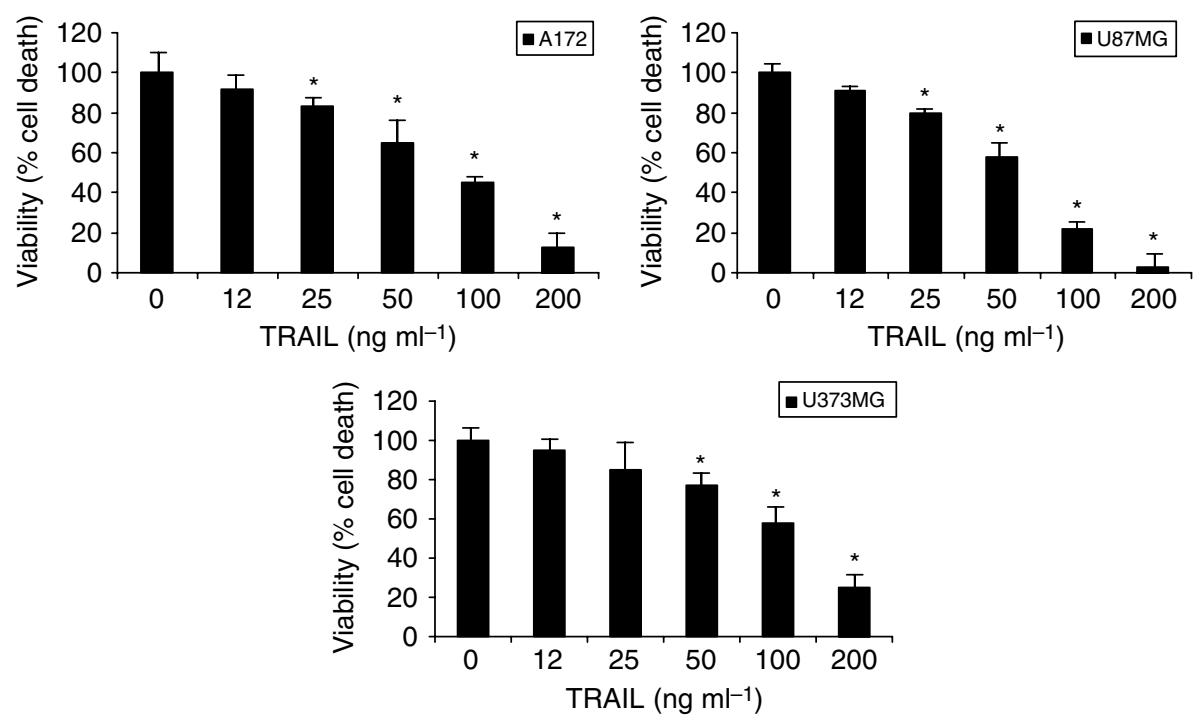

Figure I Concentration-related effects of TRAIL on the viability of the human glioblastoma cell lines AI72, U87MG or U373MG. Vertical bars are means \pm s.e.m. All experiments were run three times in duplicate. ${ }^{*} P<0.05$ compared to control (one-way ANOVA followed by Duncan's test). 
obtained showed that VEGF mRNA was reduced after 6,12 and $24 \mathrm{~h}$ of treatment with TRAIL. The effect of TRAIL was timerelated and peak values were observed after $12 \mathrm{~h}$ of treatment (Figure 2B).

Secondly, Western blot analysis showed a reduction in the amounts of VEGF protein in the three glioblastoma cell lines treated $24 \mathrm{~h}$ with TRAIL (Figure $3 \mathrm{~A}$ ).

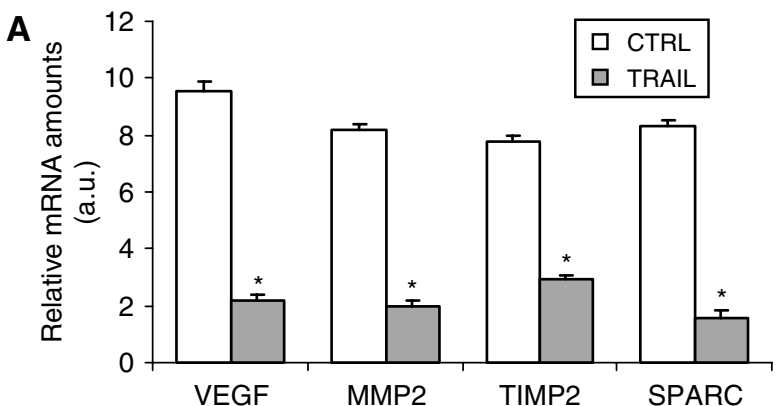

B

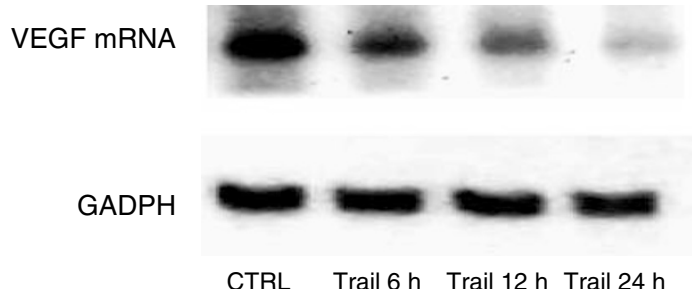

Figure 2 (A) Inhibition of VEGF, MMP-2, TIMP-2 or SPARC (open bars) mRNAs after exposure of AI 72 cells to TRAIL (closed bars), as revealed by cDNA microarray. mRNA was isolated from cells exposed for $24 \mathrm{~h}$ to $25 \mathrm{ng} \mathrm{ml}^{-1}$ of TRAIL. The results were expressed as relative amounts in arbitrary units. All data are the mean \pm s.e.m. from three different experiments run in duplicate. ${ }^{*} P<0.05$ compared to control (one-way ANOVA followed by Duncan's test). (B) Northern blot analysis of the time-related inhibition of VEGF mRNA in AI72 glioblastoma cells treated with $25 \mathrm{ng} \mathrm{ml}^{-1}$ of TRAlL. Quantitative analysis was performed normalising the sample vs GADPH mRNA levels. Time 0 was assumed as a control.
In addition, as the VEGF synthesised could not have necessarily been released in the milieu, we measured VEGF levels in the culture media of the same samples of glioblastoma cells and observed that it was actually released in substantial amounts (Figure 3B).

Nevertheless, the effects of TRAIL described so far appeared related to its capability of interfering with basal levels of VEGF protein expressed by A172, U87MG and U373MG cells. As it is known that angiogenesis is the result of a complex interplay of an array of different factors, we studied whether such inhibitory effect of TRAIL could interfere with proangiogenic factor-stimulated VEGF expression.

Thus, we first induced high VEGF expression by treating A172 cells with TNF- $\alpha$, a known inducer of VEGF expression (Ferrer et al, 1997). However, VEGF expression did not increase in the presence of TNF- $\alpha$ in A172 cells preincubated with TRAIL. The effect of the latter was time-dependent and reached its peak after $24 \mathrm{~h}$ (Figure $3 \mathrm{C}$ ).

\section{Effects of TRAIL on normal human endothelial cells: TRAIL affects VEGF synthesis capacity and mitogenesis in HUVEC cells}

Endothelial cells respond to VEGF with mitogenesis, followed by the organisation of cells in new vessels. VEGF may either be released in the milieu either by tumour cells or by endothelial cells themselves. In order to verify whether the effects of TRAIL on VEGF production by tumour cells are actually concurring with a general antiangiogenic objective, the angiogenesis-related gene array analysis was also performed in HUVEC.

VEGF protein expression in HUVEC, which expresses both TRAIL receptors DR4 and DR5 mRNAs and proteins, was reduced after $24 \mathrm{~h}$ of treatment with TRAIL (Figure $4 \mathrm{~A}$ ), an effect paralleled by reduced proliferation of endothelial cells (Figure 4B).

TRAIL inhibits vessel formation in vitro and in vivo. To assess whether the antimitogenic effect of TRAIL on HUVEC encompasses actual blood vessel formation, we tested the effects of TRAIL in appropriate models, such as tube formation in matrigel in vitro (matrigel morphogenesis assay), as well as vessel
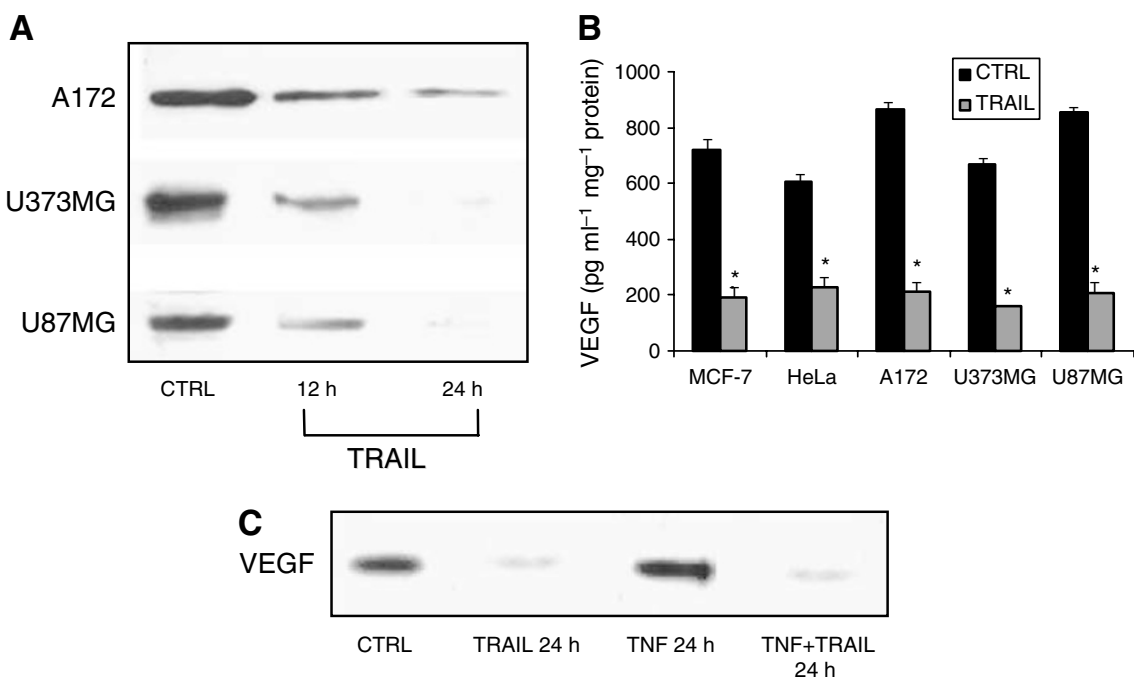

Figure 3 (A) Western blot analysis of the time course related to inhibition of the $21 \mathrm{kDa}$ VEGF protein in A I72, U373MG and U87MG glioblastoma cells treated with $25 \mathrm{ng} \mathrm{ml}^{-1}$ of TRAIL. Time zero was assumed as a control. (B) Amounts of VEGF released into the tissue culture media from either MCF-7, HeLa or A 172, U373MG and U87MG glioblastoma cells incubated $24 \mathrm{~h}$ with TRAlL $\left(25 \mathrm{ng} \mathrm{ml}^{-1}\right)$. All data are the mean + s.e.m. from three different experiments run in duplicate. $* P<0.05$ vs control (zero concentration; one-way ANOVA followed by Duncan's test). (C) Inhibitory effect of TRAlL upon the TNF- $\alpha$-stimulated VEGF expression in AI 72 glioblastoma cells. TRAIL was added to cultures for $24 \mathrm{~h}$ at a concentration of $25 \mathrm{ng} \mathrm{ml}^{-1}$. TNF- $\alpha$ was used at a concentration of $25 \mathrm{ng} \mathrm{ml}^{-1}$. 


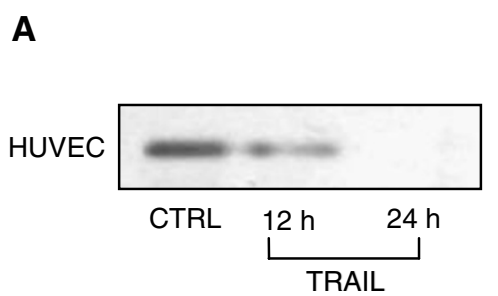

C

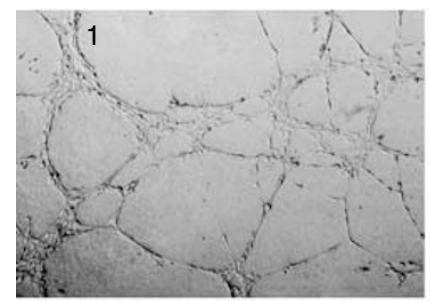

CTRL
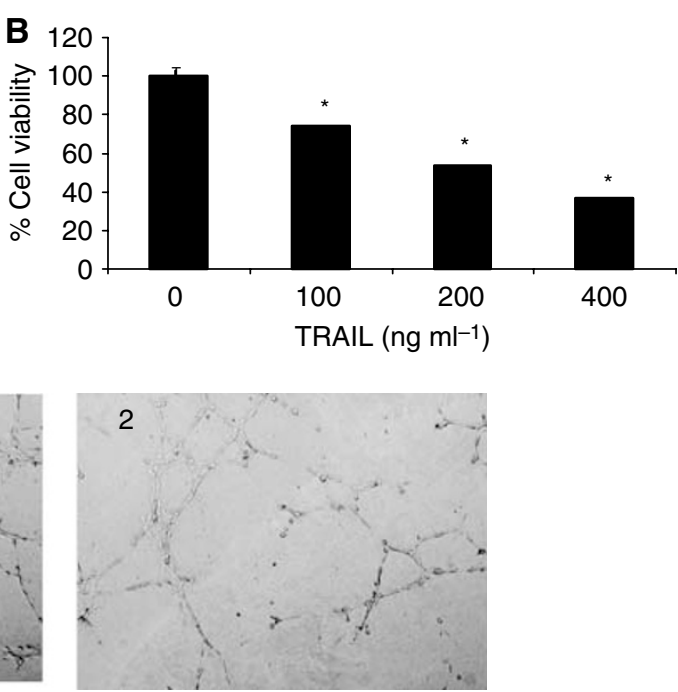

TRAIL (200 $\left.\mathrm{ng} \mathrm{m}^{-1}\right)$

Figure 4 (A) Western blot analysis of the time-dependent effect of TRAIL $\left(100 \mathrm{ng} \mathrm{ml}^{-1}\right)$ upon the expression of the $2 \mathrm{I} \mathrm{kDa}$ VEGF protein in HUVEC cells. (B) Concentration-dependent viability of HUVEC cultures treated $24 \mathrm{~h}$ with graded concentrations of TRAlL. All data are the mean \pm s.e.m. from three different experiments run in duplicate. $* P<0.05$ vs control (zero concentration; one-way ANOVA followed by Duncan's test). (C) Matrigel morphogenesis assay in vitro. Tube formation was evaluated in HUVEC cells grown in matrigel and either untreated (control, I) or treated for $24 \mathrm{~h} \mathrm{with} 200 \mathrm{ng} \mathrm{ml}^{-1}$ of TRAIL (2).

A
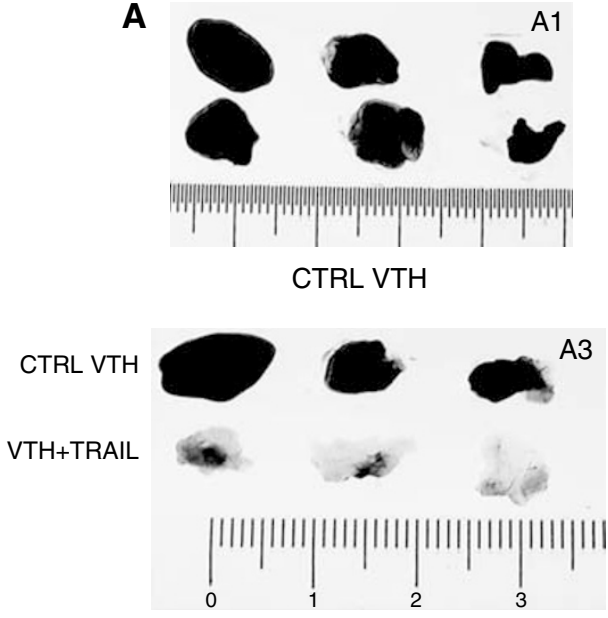
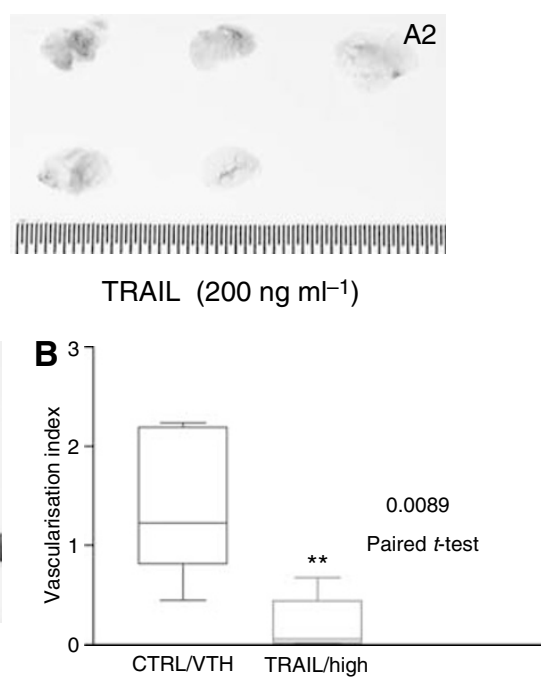

Figure 5 Matrigel angiogenesis assay in vivo. The figure illustrates the differences in size $(\mathrm{cm})$ of the vascularised areas developed locally in vivo after stimulation with different substances. All in vivo procedures were performed in accordance to the standards required by the UKCCCR guidelines for the welfare of animals in experimental neoplasia (Workman et al, 1998). (A) Effect of TRAlL upon vessel formation induced by matrigel sponges containing a proangiogenic cocktail implanted subcutaneously in vivo in the mouse. Either a proangiogenic cocktail (VTH alone, the six samples shown in AI), TRAIL at a concentration of $200 \mathrm{ng} \mathrm{ml}^{-1}$ (TRAlL alone, the six samples shown in A2), or a combination of both (in A3: VTH alone, the three samples shown in the upper row; VTH + TRAlL, the three samples in the lower row) was added to matrigel. (B) Vascularisation index calculated on the basis of the inhibitory effects of TRAIL measured in the matrigel angiogenesis assay in vivo. $* P<0.009$ (Student's ' $t$ '-test for paired differences).

formation in matrigel sponges containing a proangiogenic cocktail implanted subcutaneously in vivo in the mouse (inhibition of angiogenesis in vivo, according to the UKCCCR guidelines; Workman et al, 1998).

In the matrigel morphogenesis assay, formation of the typical cellular network occurred $6 \mathrm{~h}$ after plating (Figure 4C, photograph 1); TRAIL had concentration-dependent inhibitory effect on the morphogenesis of HUVEC cells and formation of capillary-like structures, which peaked at $200 \mathrm{ng} \mathrm{ml}^{-1}$ (Figure 4C, photograph 2).

The effects of TRAIL on angiogenesis-associated endothelial cell functions observed in vitro were confirmed in vivo in the Matrigel angiogenesis assay. Matrigel suspensions containing a proangiogenic cocktail with VEGF $\left(50 \mathrm{ng} \mathrm{ml}^{-1}\right)$, TNF- $\alpha\left(2 \mathrm{ng} \mathrm{ml}^{-1}\right)$ and heparin (VHT) were injected subcutaneously into mice. The presence of VTH in the Matrigel sponges promoted a haemorrhagic vascularisation of the gels within 4 days (Figure 5A, photograph 1). Histological examination confirmed the absence of vascularisation in the samples treated with TRAIL alone (Figure 5A, photograph 2), or the blunted angiogenesis also in the presence of the angiogenic cocktail VTH (Figure 5A, photograph 3). Quantification of the extent of angiogenesis by haemoglobin content measurement showed that TRAIL 
(200 $\left.\mathrm{ng} \mathrm{ml}^{-1}\right)$ significantly $(P<0.0089$; paired $t$-test $)$ reduced the angiogenic response if compared to the positive control (Figure 5B).

Effects of TRAIL on the expression of the MMP-2 and its inhibitor TIMP-2, and the invasiveness regulator protein SPARC in human glioblastoma cell lines

The angiogenic process appears closely related to the capacity of the tumour itself to express local invasiveness. Interestingly, gene array analysis showed that mRNA levels of both metalloproteinase MMP-2 and its inhibitor TIMP-2 were reduced in A172, U87MG and U373MG cells treated for $24 \mathrm{~h}$ with TRAIL.

Thus, we first assessed the amounts of intracellular MMP-2 by Western blot analysis of proteins. The results indicated that TRAIL induces a time-dependent decrease in intracellular levels of the enzyme. Peak of TRAIL effect occurred at $24 \mathrm{~h}$ (Figure 6, upper bands).

Along with the MMP-2, we studied the expression of its protein inhibitor TIMP-2, whose expression was also decreased in the gene array analysis.

Western blot analysis of TIMP-2 in A172, U87MG and U373MG cells treated with TRAIL resulted in decreased levels of TIMP-2 protein. The effect of TRAIL was time-dependent. Peak of the inhibitory effect was at $24 \mathrm{~h}$ (Figure 6, middle bands).

The protein SPARC has been regarded as a promoter of local invasiveness of glioblastoma. As we have shown that TRAIL decreases angiogenesis as well as remodelling factors, we
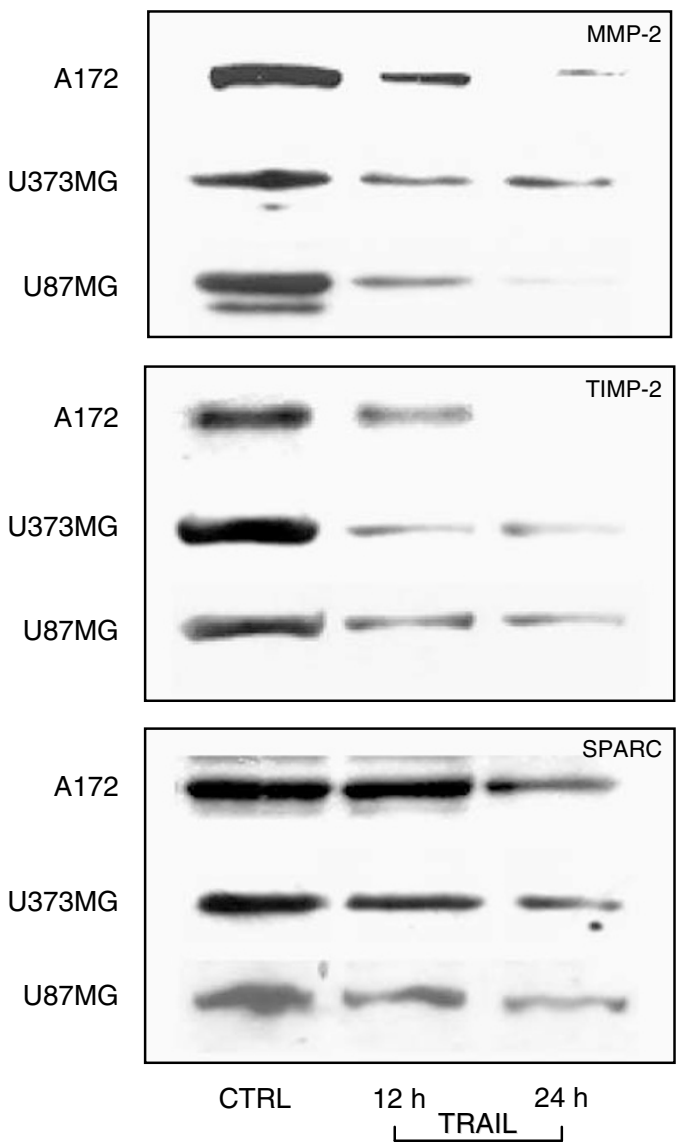

Figure 6 Western blot analysis of the inhibitory, time-dependent effects of TRAIL $\left(25 \mathrm{ng} \mathrm{ml}^{-1}\right)$ upon the expression of MMP-2 (upper panel), its inhibitor TIMP-2 (middle panel) and SPARC (lower panel) proteins in cultured A 172, U373MG and U87MG human glioblastoma cell lines. attempted to answer the question whether factors controlling invasiveness could also be affected by TRAIL.

Interestingly, gene array analysis of A172 cells treated with TRAIL showed that SPARC mRNA was reduced in comparison with untreated cells.

On the same line, Western blot analysis data showed decreased amounts of SPARC protein in A172, U87MG and U373MG cells treated with TRAIL, with a maximal effect at $24 \mathrm{~h}$ (Figure 6, lower bands).

\section{DISCUSSION}

We showed that TRAIL, a typical proapoptotic peptide molecule (Sheridan et al, 1997; Almasan and Ashkenazi, 2003), is a potent inhibitor of angiogenesis-, tissue remodelling- or invasivenessrelated factors in human glioblastoma cells. In gene array experiments, we observed that the treatment of A172 human glioblastoma cells with TRAIL reduced VEGF mRNA expression. In addition, expression of the tissue remodelling-related gene MMP-2 and its regulator TIMP-2 was also decreased, along with the expression of the invasiveness-related protein SPARC. Northern and Western blot analyses confirmed gene array data, by showing a decrease in VEGF mRNA in A172 cells, and the corresponding protein in A172, U87MG and U373MG cells treated with TRAIL.

Human glioblastoma is a richly vascularised tumour (Zagzag et al, 2000) that expresses and actively releases in the vicine tissues substantial amounts of factors promoting new vessel growth (Guerin and Laterra, 1997). As a counterproof of such biological attitude of glioblastoma, we also found that VEGF is actively released by A172, U87MG and U373MG glioblastoma cells in the tissue culture media.

Thus, from these data, it is plausible to hypothesise that VEGF released in the milieu probably reaches biologically significant concentrations, which, in light of its proangiogenic effects (Ferrara et al, 2003), are functional to maintain blood vessel formation aimed to fuel tumour enlargement.

Not only were the antiangiogenic effects of TRAIL on glioblastoma cells related to inhibition of VEGF release by tumour cells, but these were also extended to endothelial cells.

In fact, TRAIL was able to reduce the expression of VEGF protein in HUVECs. VEGF produced and released by endothelial cells is regarded as an ancillary mechanism supporting their own survival and proliferation in an autocrine fashion (Villegas et al, 2005), as it has been described, for instance, in ischaemic tissues (Seghezzi et al, 1998).

In addition to its anti-VEGF effect in HUVECs, TRAIL reduced not only HUVECs' viability but also their capability of organisation in primitive vessels, as shown by data indicating TRAIL-dependent inhibition of vessel formation in vitro and in vivo.

In support of these results, Gochuico et al (2000) described activation of an intracellular death programme, followed by apoptosis, in endothelial cells treated with concentrations of TRAIL in the range of hundreds of nanograms per millilitre, which have been shown to induce apoptosis in a variety of cells (Puduvalli et al, 2005; Shiraki et al, 2005). Thus, the apparent discrepancy of ours with other data demonstrating a mitogenic effect of TRAIL upon human endothelial cells (Secchiero et al, 2004) could be explained on the basis of the significantly lower (about 10-fold; $10 \mathrm{ng} \mathrm{ml}^{-1}$ ) concentrations used.

In fact, it has been demonstrated that low concentrations of TRAIL activate signal-transduction pathways related, respectively, to ERKs and Akt, the latter depending upon PI3K activation (Secchiero et al, 2003), whereas $\mathrm{p} 38 \mathrm{~K}$ is not activated. Besides, TRAIL at a concentration of $100 \mathrm{ng} \mathrm{ml}^{-1}$ induces apoptosis in combination with the PI3K inhibitor LY294002 in human vascular endothelial cells through activation of the extrinsic pathway, 
causing progressive cleavage of caspase- 8 and caspase- 3 with concurrent reduction of the antiapoptotic gene bcl-2 and early loss of the short form of the cellular FLIP (Alladina et al, 2005).

At any rate, we were also able to show the antiangiogenic effect of TRAIL in various in vitro models. To strenghten the hypothesis that TRAIL possessed antiangiogenic properties, we have also shown that it displays antagonistic activity upon proangiogenic cocktail-stimulated vessel formation in vivo in the mouse.

Evidence suggests that the angiogenic process is associated with a complex network of cellular and molecular events related to tissue remodelling (Sounni et al, 2002) and tumour tissue invasiveness (Nakada et al, 2003).

The human glioblastoma cell lines A172, U87MG and U373MG expressed substantial amounts of the MMP-2 (Chintala et al, 1999), which were decreased after treatment with TRAIL.

Tissue metalloproteinases, such as MMP-2, appear specifically involved in tissue remodelling. In fact, it has been shown that their expression is significantly increased in inflammation (Shamamian et al, 2001) and in tumour invasiveness and metastatisation (Turck et al, 1996) processes. Metalloproteinases are in turn regulated by inhibitory molecules (Goldman and Shalev, 2004); the balance between the two molecular families being critical for control of proteolysis (Lu et al, 2004).

Interestingly, the A172, U87MG and U373MG glioblastoma cell lines expressed high levels of the TIMP-2 metalloproteinase inhibitor and TRAIL was able to reduce such expression. Although divergent data are available regarding relationships between the expression of MMPS and the inhibitory TIMP protein family in gliomas, a number of reports claim that, along with that of MMP, TIMP overexpression is closely related to the degree of malignancy (Nakano et al, 1995; Lampert et al, 1998).

Overall, the bulk of data demonstrate that an altered ratio between TIMP-2 and MMP-2 may be related to glioblastoma invasiveness (Kachra et al, 1999).

\section{REFERENCES}

Acker T, Plate KH (2004) Hypoxia and hypoxia inducible factor (HIF) as important regulators of tumor physiology. Cancer Treat Res 117: $219-248$

Albini A, D’Agostini F, Giunciuglio D, Paglieri I, Balansky R, De Flora S (1995) Inhibition of invasion, gelatinase activity, tumor take and metastasis of malignant cells by $N$-acetylcysteine. Int J Cancer 61: $121-129$

Albini A, Fontanini G, Masiello L, Tacchetti C, Bigini D, Luzzi P, Noonan D, Stetler-Stevenson W (1994) Angiogenic potential in vivo by Kaposi sarcoma cell-free supernatants and HIV1-tat product: inhibition of KSlike lesions by TIMP-2. Acquir Immune Defic Syndrome 8: 1237-1244

Alladina SJ, Song JH, Davidge ST, Hao C, Easton AS (2005) TRAIL-induced apoptosis in human vascular endothelium is regulated by phosphatidylinositol 3-kinase/Akt through the short form of celllar FLIP and bcl-2. $J$ Vasc Res 42: $337-347$

Almasan A, Ashkenazi A (2003) Apo2L/TRAIL: apoptosis signaling, biology, and potential for cancer therapy. Cytokine Growth Factor Rev 14: $337-348$

Briggs J, Chamboredon S, Castellazzi M, Kerry JA, Bos TJ (2002) Transcriptional upregulation of SPARC, in response to c-Jun overexpression,contributes to increased motility and invasion of MCF7 breast cancer cells. Oncogene 21: $7077-7091$

Bussolino F, Mantovani A, Persico G (1998) Molecular mechanisms of blood vessels formation. TrendsBiochem Sci 22: $251-258$

Chintala SK, Tonn JC, Rao JS (1999) Matrix metalloproteinases and their biological function in human gliomas. Int J Dev Neurosci 17: 495 - 502

De Ridder LI, Laerum OD, Mork SJ, Bigner DD (1987) Invasiveness of human glioma cell lines in vitro: relation to tumorigenicity in athymic mice. Acta Neuropathol 72: 207-213

Ferrara N (1993) Vascular endothelial growth factor. Trends Cardiovasc Med 3: $244-250$

Ferrara N (2005) The role of VEGF in the regulation of physiological and pathological angiogenesis. EXS 94: 209-303
It could be reasoned that the inhibitory effect of TRAIL upon the metalloproteinase system is added to its antiangiogenic effects reported earlier. In fact, factors controlling tumour invasiveness act in a concerted way with those related to both angiogenesis and tissue remodelling (Finn et al, 1997). Interestingly, gene array data from cells treated with TRAIL showed decreased expression of the invasiveness inhibitor protein SPARC. Although the latter normally inhibits cell invasiveness processes (Hasselaar and Sage, 1992), it displays opposite effects in tumour cells (Briggs et al, 2002), including glioblastoma (Vajkoczy et al, 2000). For this reason, SPARC has been regarded as an enhancer of the capability of glioblastomas to localise in multiple sites of the brain (Schultz et al, 2002).

In summary, TRAIL is a potent inhibitor of the orchestra of factors controlling angiogenesis, invasiveness and tissue remodelling in various human glioblastoma cell lines. The antiangiogenic effects of TRAIL include inhibition of VEGF release from tumour cells, as well as an antimitogenic effect upon endothelial cells. In addition, TRAIL potently suppresses the expression of tissue remodelling factors, such as MMP-2 and TIMP-2, as well as of those promoting glioblastoma invasiveness, such as SPARC.

In conclusion, the TRAIL system could be regarded as a potential target for novel glioblastoma therapy aimed at disruption of the ensemble of factors promoting angiogenesis, tissue remodelling and tumour invasiveness.

\section{ACKNOWLEDGEMENTS}

We thank Dr Napoleone Ferrara, Genentech Inc., South San Francisco, CA, USA, for his helpful advice and Ms Angela Smith for careful editorial assistance. The work was supported by AIRC, CoRiBiA, University of Catania.
Ferrara N, Davis Smyth T (1997) The biology of vascular endothelial growth factor. Endocr Rev 18: 4-25

Ferrara N, Gerber HP, LeCouter J (2003) The biology of VEGF and its receptors. Nat Med 9: 669-676

Ferrer FA, Miller LJ, Andrawis RI, Kurtzman SH, Albertsen PC, Laudone VP, Kreutzer DL (1997) Vascular endothelial growth factor (VEGF) expression in human prostate cancer: in situ and in vitro expression of VEGF by human prostate cancer cells. J Urol 157: 2040-2041

Fillmore HL, VanMeter TE, Broaddus WC (2001) Membrane-type matrix metalloproteinases (MT-MMPs): expression and function during glioma invasion. J Neurooncol 53: 213-235

Finn PE, Bjerkvig R, Pilkington GJ (1997) The role of growth factors in the malignant and invasive progression of intrinsic brain tumours. Anticancer Res 17: $4163-4172$

Folkman J (1995) Angiogenesis in cancer, vascular, rheumatoid and other disease. Nat Med 1: 27-31

Gochuico BR, Zhang J, Ma BY, Marshak-Rothstein A, Fine A (2000) TRAIL expression in vascular smooth muscle. Am J Physiol Lung Cell Mol Physiol 278: $1045-1050$

Goldman S, Shalev E (2004) MMPS and TIMPS in ovarian physiology and pathophysiology. Front Biosci 9: 2474-2483

Golembieski WA, Rempel SA (2002) cDNA array analysis of SPARCmodulated changes in glioma gene expression. Neurooncol 60: 213-226

Guerin C, Laterra J (1997) Regulation of angiogenesis in malignant gliomas. EXS 79: 47-64

Hasselaar P, Sage HE (1992) SPARC antagonizes the effect of basic fibroblast growth factor on the migration of bovine aortic endothelial cells. J Cell Biochem 49: 272-283

Jaffe EA, Nachman RL, Becker CG, Minick CR (1973) Culture of human endothelial cells derived from umbilical veins. Identification by morphologic and immunologic criteria. J Clin Invest 52: 2745-2756 
Kachra Z, Beaulieu E, Delbecchi L, Mousseau N, Berthelet F, Moumdjian R, Del Maestro R, Beliveau R (1999) Expression of matrix metalloproteinases and their inhibitors in human brain tumors. Clin Exp Metast 17: $555-566$

Kasuga C, Ebata T, Kayagaki N, Yagita H, Hishii M, Arai H, Sato K, Okumura K (2004) Sensitization of human glioblastomas to tumor necrosis factor-related apoptosis-inducing ligand (TRAIL) by NF- $\kappa \mathrm{B}$ inhibitors. Cancer Sci 95: 840 - 844

Lampert K, Machein U, Machein MR, Conca W, Peter HH, Volk B (1998) Expression of matrix metalloproteinases and their tissue inhibitors in human brain tumors. Am J Pathol 153: 429-437

Li JH., Kirkiles-Smith NC, McNiff JM, Pober JS (2003) TRAIL induces apoptosis and inflammatory gene expression in human endothelial cells. J Immunol 171: $1526-1533$

Lu KV, Jong KA, Rajasekaran AK, Cloughesy TF, Mischel PS (2004) Upregulation of tissue inhibitor of metalloproteinases (TIMP)-2 promotes matrix metalloproteinase (MMP)-2 activation and cell invasion in a human glioblastoma cell line. Lab Invest 84: 8-20

Nabors LB, Suswam E, Huang Y, Yang X, Johnson MJ, King PH (2003) Tumor necrosis factor alpha induces angiogenic factor up-regulation in malignant glioma cells: a role for RNA stabilization and HuR. Cancer Res 63: $4181-4187$

Nakada M, Okada Y, Yamashita J (2003) The role of matrix metalloproteinases in glioma invasion. Front Biosci 8: 261-269

Nakano A, Tani E, Miyazaki K, Yamamoto Y, Furuyama J (1995) Matrix metalloproteinases and tissue inhibitors of metalloproteinases in human gliomas. J Neurosurg 83: 298-307

Nitsch R, Bechmann I., Deisz RA, Haas D, Lehmann TN, Wendling U, Zipp F (2000) Human brain-cell death induced by tumournecrosis-factor-related apoptosis-inducing ligand (TRAIL). Lancet 356: $827-828$

Passaniti A, Taylor R, Pili R, Guo Y, Long P, Haney J (1992) A simple, quantitative method for assessing angiogenesis and antiangiogenic agents using reconstituted basement membrane, heparin, and fibroblast growth factor. Lab Invest 67: 519-528

Pollack IF, Erff M, Ashkenazi A (2001) Direct stimulation of apototic signaling by soluble Apo2L/Tumor necrosis factor-related apoptosisinducing ligand leads to selective killing of glioma cells. Clin Cancer Res 7: $1362-1369$

Puduvalli VK, Sampath D, Bruner JM, Nangia J, Xu R, Kyritsis AP 2005)) TRAIL-induced apoptosis in gliomas is enhanced by Akt-inhibition and is independent of JNK activation. Apoptosis 10: 233-243

Risau W (1997) Mechanisms of angiogenesis. Nature 386: 671-674

Schultz C, Lemke N, Ge S, Golembieski WA, Rempel SA (2002) Secreted protein acidic and rich in cysteine promotes glioma invasion and delays tumor growth in vivo. Cancer Res 62: 6270-6277

Secchiero P, Gonelli A, Carnevale E, Corallini F, Rizzardi C, Zacchigna S, Melato M, Zauli G (2004) Evidence for a proangiogenic activity of TNFrelated apoptosis-inducing ligand. Neoplasia 6: $364-373$

Secchiero P, Monelli A, Carnevale E, Milani D, Pandolfi A, Zella D, Zauli G (2003) TRAIL promotes the survival and the proliferation of primary human vascular endothelial cells by activating the Akt and ERK pathways. Circulation 107: 2250-2256

Seghezzi G, Patel S, Ren CJ, Gualandris A, Pintucci G, Robbins ES, Shapiro RL, Galloway AC, Rifkin DB, Mignatti P (1998) Fibroblast growth factor2 (FGF-2) induces vascular endothelial growth factor (VEGF) expression in the endothelial cells of forming capillaries: an autocrine mechanism contributing to angiogenesis. J Cell Biol 141: 1659-1673

Shamamian P, Schwartz JD, Pocock BJ, Monea S, Whiting D, Marcus SG, Mignatti P (2001) Activation of progelatinase A (MMP-2) by neutrophil elastase, cathepsin $\mathrm{G}$, and proteinase-3: a role for inflammatory cells in tumor invasion and angiogenesis. J Cell Physiol 189: 197-206

Sheridan JP, Marsters SA, Pitti RM, Gurney A, Skubatch M, Baldwin D (1997) Control of TRAIL-induced apoptosis by a family of signalling and decoy receptor. Science 277: 818-821

Shiraki K, Yamanaka T, Inoue H, Kawakita T, Enokimura N, Okano H, Sugimoto K, Murata K, Nakano T (2005) Expression of TNF-related apoptosis-inducing ligand in human hepatocellularcarcinoma. Int $J$ Oncol 26: $1273-1281$

Sounni NE, Devy L, Hajitou A (2002) MT1-MMP expression promotes tumor growth and angiogenesis through an up-regulation of vascular endothelial growth factor expression. FASEB J 16: 555-564

Turck J, Pollock AS, Lee LK, Marti HP, Lovett DH (1996) Matrix metalloproteinase 2 (gelatinase A) regulates glomerular mesangial cell proliferation and differentiation. J Biol Chem 271: 15074-15083

Vajkoczy P, Menger MD, Goldbrunner R, Ge S, Fong TA, Vollmar B, Schilling L, Ullrich A, Hirth KP, Tonn JC, Schmiedek P, Rempel SA (2000) Targeting angiogenesis inhibits tumor infiltration and expression of the pro-invasive protein SPARC. Int J Cancer 87: 261-268

Vanderslice P, Munsch CL, Rachal E, Erichsen D, Sughrue KM, Truong AN, Wygant JN, McIntyre BW, Eskin SG, Tilton RG, Polverini PJ (1998) Angiogenesis induced by tumor necrosis factor-agr, is mediated by alpha4 integrins. Angiogenesis 3: 265-275

VanMeter TE, Rooprai HK, Kibble MM, Fillmore HL, Broaddus WC, Pilkington GJ (2001) The role of matrix metalloproteinase genes in glioma invasion: co-dependent and interactive proteolysis. J Neurooncol 53: $187-202$

Villegas G, Lange-Sperandio B, Tufro A (2005) Autocrine and paracrine functions of vascular endothelial growth factor (VEGF) in renal tubular epithelial cells. Kidney Int 67: 449-457

Workman P, Twentyman P, Balkwill F, Balmain A, Chaplin D, Double J, Embleton J, Newell D, Raymond R, Stables J, Stephens T, Wallace J (1998) United Kingdom co-ordinating committee on cancer research (UKCCCR) guidelines for the welfare of animals in experimental neoplasia (second edition). Br J Cancer 77: 1 - 10

Zagzag D, Friedlander DR, Margolis B, Grumet M, Semenza GL, Zhong H, Simons JW, Holash J, Wiegand SJ, Yancopoulos GD (2000) Molecular events implicated in brain tumor angiogenesis and invasion. Pediatr Neurosurg 33: $49-55$

Zheng SX, Zhou LJ, Zhu XZ, Jin YX (2000) Antisense oligodeoxynucleotide inhibits vascular endothelial growth factor in human glioma cells. Acta Pharmacol Sin 21: $211-214$ 